\title{
Pressureless Bonding Using Sputtered Ag Thin Films
}

\author{
CHULMIN OH, ${ }^{1,2,3}$ SHIJO NAGAO ${ }^{2}$ and KATSUAKI SUGANUMA ${ }^{2}$ \\ 1.-Department of Adaptive Machine Systems, Osaka University, 8-1 Mihogaoka, Ibaraki, Osaka, \\ Japan. 2.-Institute of Scientific and Industrial Research, Osaka University, 8-1 Mihogaoka, \\ Ibaraki, Osaka, Japan. 3.—e-mail: cmoh@eco.sanken.osaka-u.ac.jp
}

To improve the performance and reliability of power electronic devices, particularly those built around next-generation wide-bandgap semiconductors such as $\mathrm{SiC}$ and $\mathrm{GaN}$, the bonding method used for packaging must change from soldering to solderless technology. Because traditional solders are problematic in the harsh operating conditions expected for emerging hightemperature power devices, we propose a new bonding method in this paper, namely a pressureless, low-temperature bonding process in air, using abnormal grain growth on sputtered Ag thin films to realize extremely high temperature resistance. To investigate the mechanisms of this bonding process, we characterized the microstructural changes in the Ag films over various bonding temperatures and times. We measured the bonding properties of the specimens by a die-shear strength test, as well as by x-ray diffraction measurements of the residual stress in the $\mathrm{Ag}$ films to show how the microstructural developments were essential to the bonding technology. Sound bonds with high die strength can be achieved only with abnormal grain growth at optimum bonding temperature and time. Pressureless bonding allows for production of reliable high-temperature power devices for a wide variety of industrial, energy, and environmental applications.

Key words: Bonding, thin films, abnormal grain growth, semiconductor devices

\section{INTRODUCTION}

Over the past few decades, soldering has been widely used to bond components in electronics packages. In recent years, however, environmental regulations such as Restriction of Hazardous Substances (RoHS) have mandated a change from traditional $\mathrm{Pb}$-Sn solders to Pb-free solders. ${ }^{1} \mathrm{Sn}-\mathrm{Ag}-\mathrm{Cu}$ solders have been adopted because of their relatively low process temperature and reasonable cost when used to mass-produce electronics. ${ }^{2-4}$ In power electronics, researchers have investigated alternatives to high- $\mathrm{Pb}$ solders for SiC- and GaN-based high-temperature wide-bandgap (WBG) semiconductor devices. ${ }^{5-7}$ To overcome the inherent limits of soldering, alternative bonding processes have been

(Received April 30, 2014; accepted July 26, 2014; published online August 26, 2014) developed, drastically improving the high-temperature reliability of power devices and modules suitable for electric vehicles.

Transient liquid phase (TLP) bonding is a candidate alternative technology. ${ }^{8,9}$ In TLP bonding, the starting materials are melted at a relatively low temperature and then reacted to form intermetallic compounds (IMCs) under applied pressure, increasing the melting point of the bonded layer. This increased melting point means that the IMCs generated at the bonding interface can withstand elevated operating temperatures. However, IMCs often affect the electrical and thermal performance of power devices because they can decrease thermal and electrical conductivity. IMCs can also weaken the mechanical properties of the device, particularly when interfacial IMCs continually grow by thermal aging in the operation environment.

Another bonding method is sintering metal pastes made of metal nanoparticles, mostly Ag nanoparticles, microflakes, or some combination; bonds produced 
using this method have exhibited excellent thermal and electrical properties. ${ }^{10,11}$ Bonding with $\mathrm{Ag}$ paste sintering can be done at relatively low bonding temperatures under applied pressure, ensuring high operating temperatures for WBG semiconductor devices. ${ }^{1,11}$ In these bonds, the sintered interfacial microstructure is composed of aggregated Ag particles with microvoids; its exact properties depend on the solvent, organic dispersant, binder, and other processing conditions. It is essential to design the $\mathrm{Ag}$ particle synthesis and tune the paste suitably for the bonding process, rather than optimizing the bonding conditions. Simultaneously optimizing both the bonding process and metal particle synthesis demands extreme effort to explore the various combinations of material and process parameters.

Another bonding method is $\mathrm{Cu}-\mathrm{Cu}$ direct bonding, which uses diffusion of metal atoms. ${ }^{12,13}$ In this method, the bonding interface forms by interdiffusion of $\mathrm{Cu}$ atoms, available under high temperature and pressure, in an ultrahigh vacuum to prevent oxidation. ${ }^{12}$ Room-temperature $\mathrm{Cu}-\mathrm{Cu}$ bonding has been rarely studied, and bonding in an ultrahigh vacuum induces an additional surface activation process. ${ }^{13}$ These processes have many issues to be solved before mass production, mainly the high cost and low throughput of bonding in an ultrahigh vacuum, caused by the surface activation process. This bonding technology must be studied to make it practical for producing high volumes of power devices that will operate reliably in harsh working environments.

We have previously proposed and developed an emerging bonding technology for power device packaging, namely a pressureless, low-temperature bonding method using Ag films. ${ }^{14,15}$ We realized this pressureless Ag film direct bonding by converting hillock formation into abnormal grain growth accompanied by stress relaxation. ${ }^{16}$ The evolution of the hillock microstructure in the Ag films plays a key role in the pressureless bonding process, but its details have not yet been revealed. In this study, we investigated the development of the $\mathrm{Ag}$ film microstructure under various bonding conditions. We studied how the bond strength depends on the process temperature and time, revealing an optimum process window. Our results open the way for applying $\mathrm{Ag}$ film pressureless bonding to a wide range of reliable, high-temperature power devices using WBG semiconductors in the near future.

\section{EXPERIMENTAL PROCEDURES}

A 4-inch Si wafer of 0.5-mm thickness was diced into $6 \mathrm{~mm} \times 6 \mathrm{~mm}$ and $3 \mathrm{~mm} \times 3 \mathrm{~mm}$ pieces to act as dummy chips and substrates, respectively. After cleaning the specimens for $5 \mathrm{~min}$ in ultrasonicated acetone, a $0.04-\mu \mathrm{m}$ Ti film was deposited on both the chip and substrate using radiofrequency $(\mathrm{RF})$ sputtering at $6 \mathrm{~nm} / \mathrm{min}$. Subsequently, a $1.0-\mu \mathrm{m} \mathrm{Ag} \mathrm{film}$ was deposited on the $\mathrm{Ti}$ adhesion layer using directcurrent (DC) sputtering at $30 \mathrm{~nm} / \mathrm{min}$. The base pressure of the vacuum chamber was $<5.0 \times$ $10^{-3} \mathrm{~Pa}$, and the Ar flow rate was $10 \mathrm{sccm}$. During deposition, the substrate temperature was kept at room temperature by a cooling system in the sputtering equipment.

A droplet of ethylene glycol was spread on the substrate to promote good contact between the chip and substrate. Then, a Si chip was mounted on the Si substrate, facing the Ag films towards each other. The mounted specimens were placed in an oven in air without an applied load. To find the lowest bonding temperature that produced a sound bond, we increased the bonding temperature in steps of $10^{\circ} \mathrm{C}$ up to $230^{\circ} \mathrm{C}$, keeping a constant process time of $1 \mathrm{~h}$. After finding the initial bonding temperature, the bonding temperature was increased in steps of $50^{\circ} \mathrm{C}$ from $250^{\circ} \mathrm{C}$ up to $400^{\circ} \mathrm{C}$ to evaluate the bonding properties at various process temperatures. The shear strength was highest at a bonding temperature of $250^{\circ} \mathrm{C}$, which we adopted for further experiments with process time variation from $10 \mathrm{~min}$ to $120 \mathrm{~min}$. The shear strength of the bonded specimens was measured by die-shear tests (Dage 4000) with shear rate of $50 \mu \mathrm{m} / \mathrm{s}$ and shear height of the
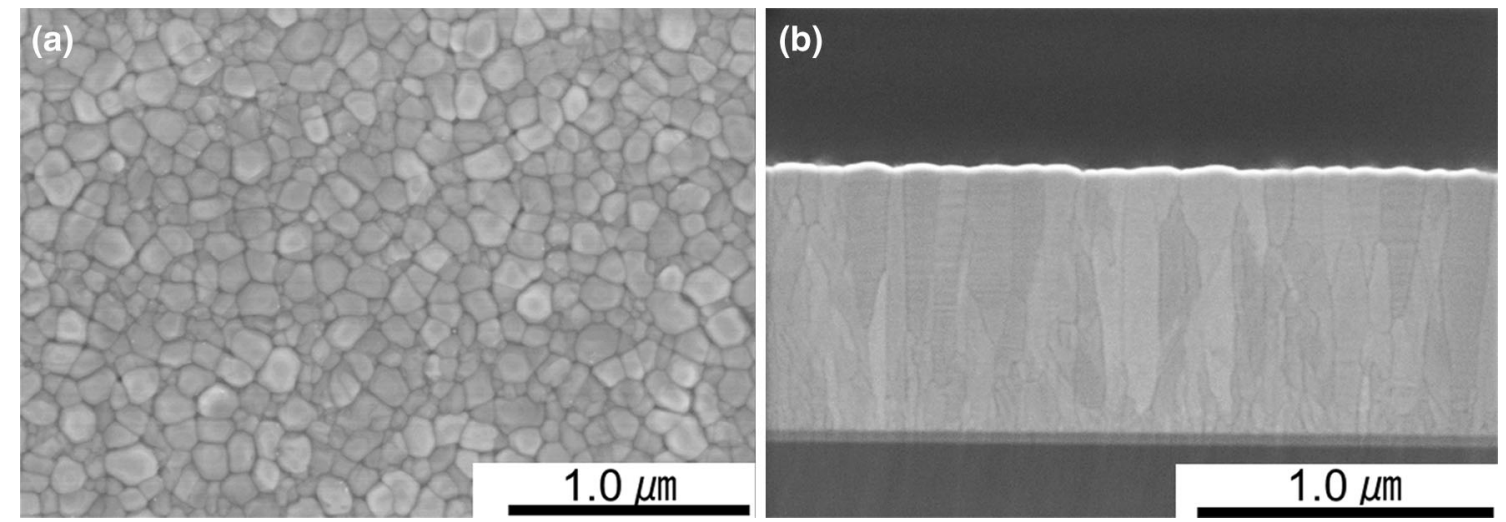

Fig. 1. Fine-grained microstructure of as-deposited Ag films: (a) SEM micrograph of typical film surface and (b) cross-sectional columnar structure. 
chip of $1.2 \mu \mathrm{m}$ from the surface. For each bonding condition, we measured five bonded specimens using the die-shear test.

Scanning electron microscopy (SEM) was used to assess how the surface and cross-sectional morphologies of the Ag film changed with the bonding process parameters. The number and size of the hillocks were measured using $20 \mu \mathrm{m} \times 25 \mu \mathrm{m}$ areas from SEM micrographs. X-ray diffraction (XRD) was used to measure the texture of the sputtered Ag films. These XRD results were also used to calculate the residual stress of the sputtered Ag film at room temperature, using the $\sin ^{2} \psi$ method. ${ }^{17}$ Five specimens were measured to determine the residual stress for each bonding condition. The diffraction peak at $2 \theta=156.87^{\circ}$ was selected for this stress measurement, generated by monochromatic $\mathrm{Cu} \mathrm{K}_{\alpha 1}$ radiation at $40 \mathrm{kV}$ and $30 \mathrm{~mA}$. At lower $\psi$ angles, the diffraction intensity was mainly contributed by (333) rather than (115) because of strong $\langle 111\rangle$ preferential orientation of the sputtered Ag thin films, although the (333) and (115) diffraction peaks overlap. In this case, the strained lattice spacing $d_{\psi}^{333}$ caused by film stress shifted the $2 \theta$ diffraction peak, written as a function of $\psi$ as

$$
d_{\psi}^{h k l}=d_{0}^{h k l}\left(1+\sigma\left[2 s_{1}^{h k l}+\frac{1}{2} s_{2}^{h k l} \sin ^{2} \psi\right]\right),
$$

where $d_{0}^{h k l}$ is the unstressed lattice spacing, and $s_{1}^{h k l}$ and $s_{2}^{h k l}$ are the x-ray elastic constants along $\langle h k l\rangle .{ }^{17}$ Nonlinear least-squares fitting of Eq. 1 was used to determine the film stress $\sigma$, where $\psi$ is limited to $\sin ^{2} \psi=0.08$ with the bulk Ag cubic lattice constant $a=0.40853 \mathrm{~nm}$ for the unstressed bulk spacing $d_{0}^{333}=0.0786 \mathrm{~nm}$. The x-ray elastic constants were calculated using the Reuss model as $s_{1}^{333}=-2.516 \mathrm{TPa}^{-1}$ and $s_{2}^{333}=21.505 \mathrm{TPa}^{-1}$ from the anisotropic elastic constants $\left\{C_{i j}\right\}$ of $\mathrm{Ag} .{ }^{18}$ Note that the calculated film stress $\sigma$ includes the effect of the diffraction peak shift at the origin $(\psi=0)$ through the least-squares fitting using Eq. 1. Five additional bonded specimens were prepared at each bonding conditions for SEM observation and residual stress measurements. (a)

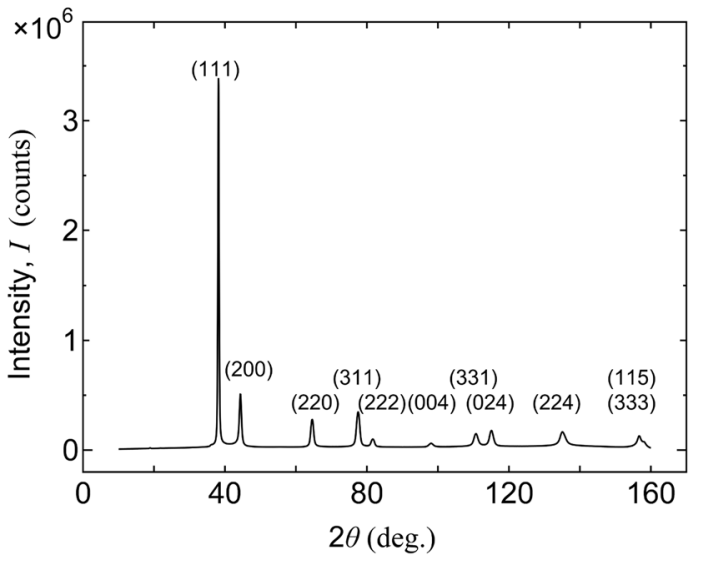

(b)

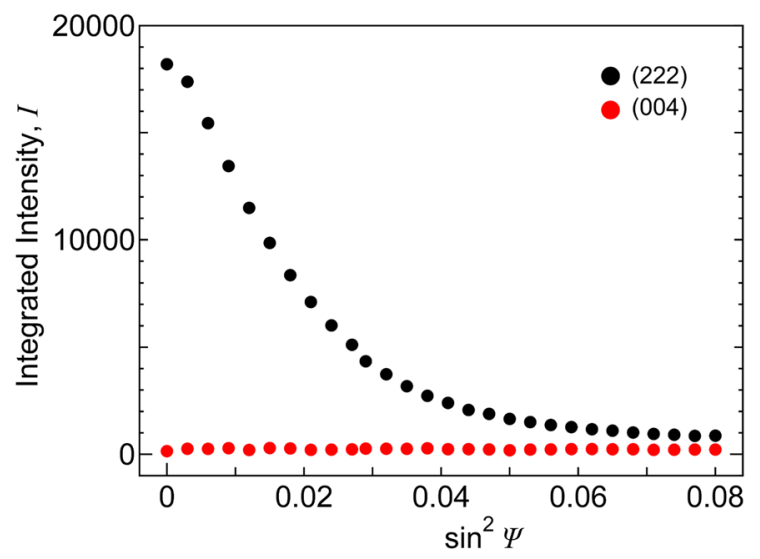

Fig. 2. (a) XRD profile obtained for as-deposited Ag films; (b) integrated intensity of the (222) and (004) peaks, varying with inclination angle $\psi$ to the sample surface, showing strong $\langle 111\rangle$ axis preference normal to the surface.
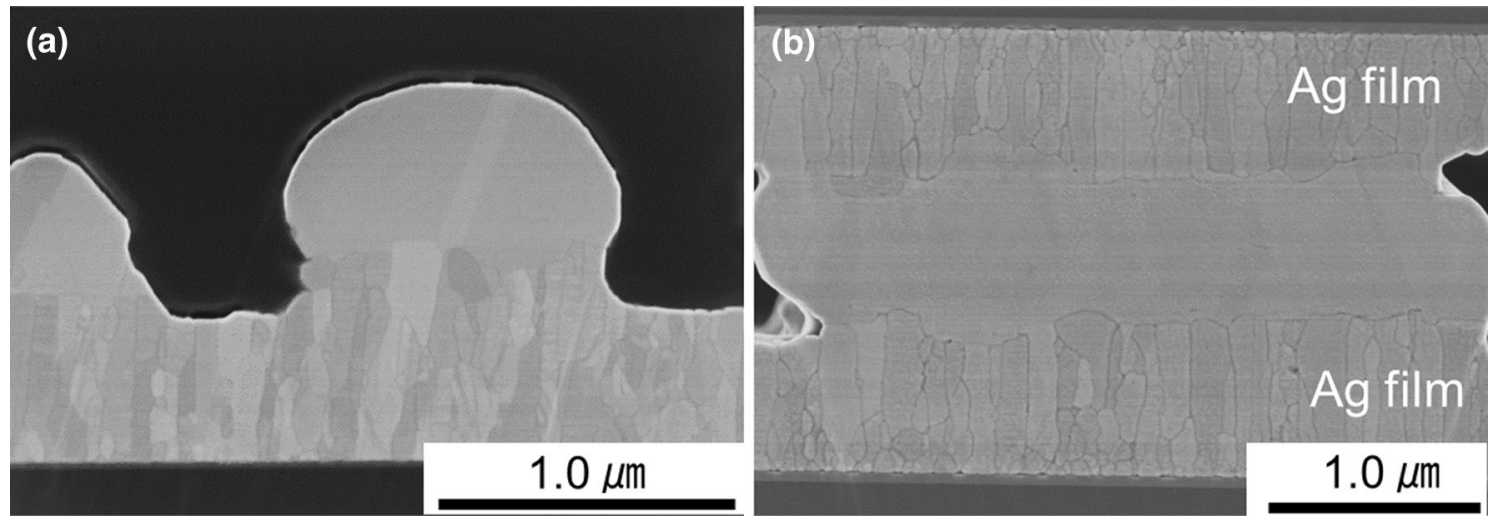

Fig. 3. Cross-sectional SEM micrograph of (a) hillock growth in Ag films and (b) abnormal growth at the bonding interface. Hillocks generated by heat treatment transformed into abnormal grains, producing a sound interface with high bond strength. 


\section{RESULTS AND DISCUSSION}

\section{Microstructure of As-Deposited Ag Films and Bonded Ag Films}

Figure 1a shows the presence of fine $(\sim 100 \mathrm{~nm})$ grains on the surface of the sputtered Ag film. The grain size distribution was homogeneous across the surface of each Si chip and substrate. Figure $1 b$ shows typical cross-sectional SEM images of the Ag grain structure. Many grains appear columnar, although some equiaxed grains appeared near the Ti layer. The quality of the columnar structure in deposited Ag films may depend on the film thickness. ${ }^{19}$

Figure 2a shows a typical XRD profile of as-deposited Ag films, matching the diffraction pattern of the face-centered cubic (fcc) Ag crystal structure. The $2 \theta$ profile clearly indicates the polycrystalline nature of the deposited film, but the (111) diffraction peak was remarkably higher than the others. We confirmed the preferential $\langle 111\rangle$ orientation of the sputtered Ag films by plotting the integrated intensity of the (222) and (004) peaks as a function of $\sin ^{2} \psi$, as shown in Fig. 2b. The differing behavior of the two peaks indicates a preferential $\langle 111\rangle$ axis normal to the film surface. Moreover, the integrated (222) intensity was higher than that of (004) over the whole $\sin ^{2} \psi$ range available for $\mathrm{Cu} \mathrm{K} \mathrm{K}_{\alpha} \mathrm{x}$-rays, even though the calculated integrated intensities were similar for the fcc
Ag crystal structure factors. This preference comes from the (111) plane having the lowest surface energy in the fcc structure because of thermodynamics. The strong $\langle 111\rangle$ orientation also supports our internal stress analysis by $\sin ^{2} \psi$ measurements, using only (333) diffraction and neglecting the overlapping (115) peak.

Figure 3a shows typical morphology changes in the microstructure after heat treatment, revealing obvious hillock growth of large Ag crystals. Such hillock growth on sputtered films has been observed during progressive relaxation of compressive stress during thermal cycling. ${ }^{20}$ In our case, these hillocks on the Ag films led to large abnormal grain growth, starting from fine grains in the as-deposited $\mathrm{Ag}$ films. When samples coated with $\mathrm{Ag}$ contacted each other without any applied pressure, during heating the interfacial gap filled with abnormally grown grains, tuned from the hillocks rooted on with the original columnar structures (Fig. 3b). The sound interface composed of large bulk-like $\mathrm{Ag}$ grains joining the two surfaces ensures extremely high bond strength.

\section{Changes in Microstructural Evolution and Bonding Properties with Bonding Temperature}

Figure 4 shows how the microstructure of the as-deposited Ag films changed after heat treatment
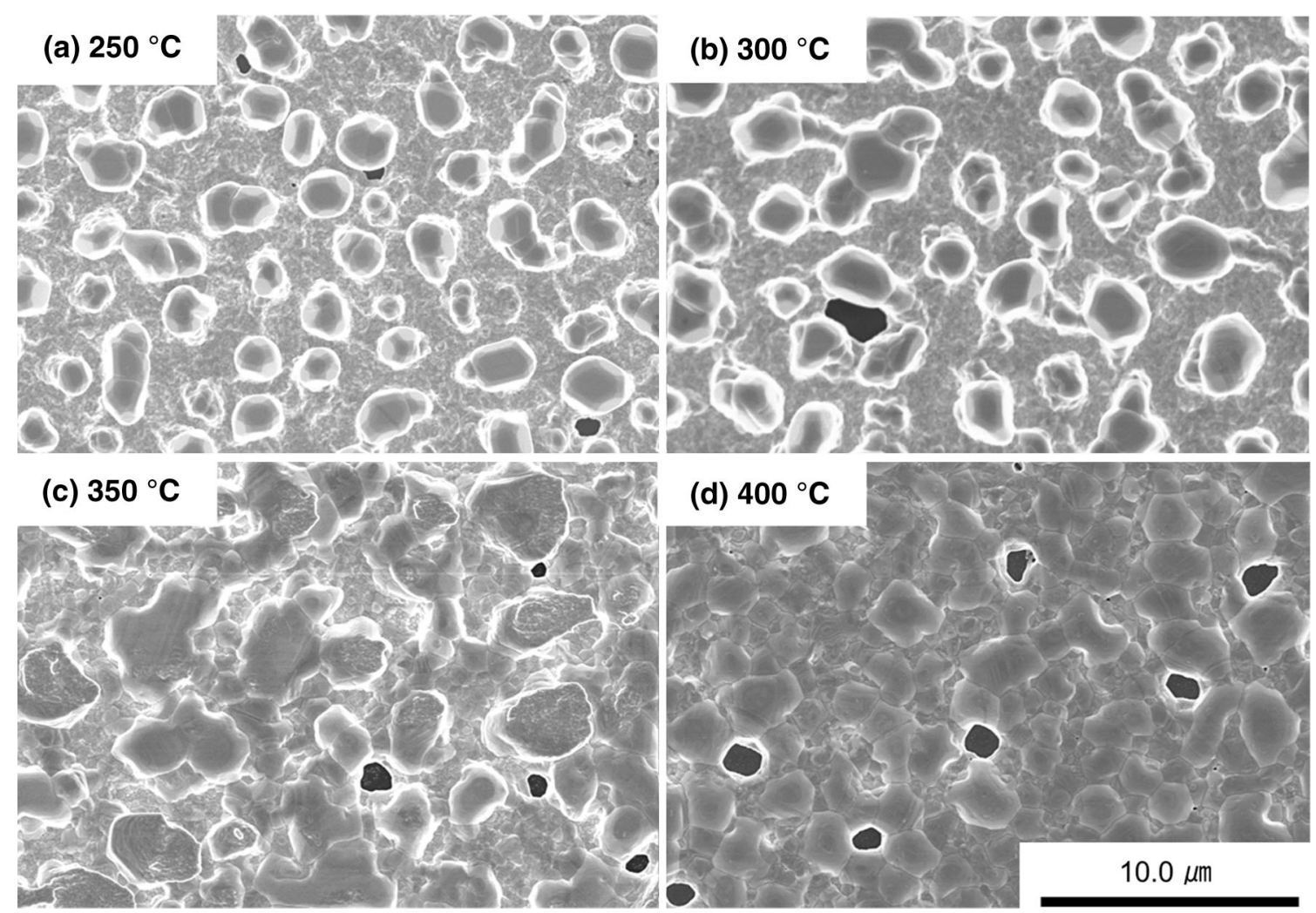

Fig. 4. SEM micrographs of the microstructural evolution of $\mathrm{Ag}$ films at various bonding temperatures: (a) $250^{\circ} \mathrm{C}$, (b) $300^{\circ} \mathrm{C},(\mathrm{c}) 350^{\circ} \mathrm{C}$, and (d) $400^{\circ} \mathrm{C}$. As the temperature increased, the growth mode of the microstructure changed from hillock formation to grain growth. 
for $1 \mathrm{~h}$ at various temperatures. In films heated at $250^{\circ} \mathrm{C}$, the optimum bonding temperature, we observed massive hillock growth. At elevated temperatures during bonding, stress in the sputtered $\mathrm{Ag}$ film accumulates because of a large mismatch in the coefficient of thermal expansion (CTE) between the film and substrate; the CTE of $\mathrm{Ag}$ is ten times larger than that of Si. The compressive stress induced during heating causes stress

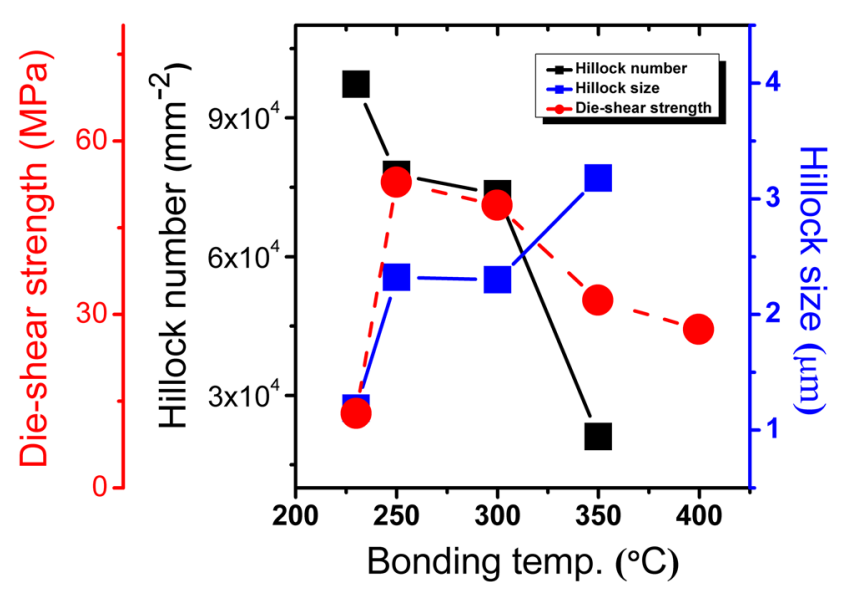

Fig. 5. Correlation of the size and number of hillocks with the measured die-shear strength of bonded samples. The shear strength is shown as a red line. The highest die-shear strength was achieved at a bonding temperature of $250^{\circ} \mathrm{C}$. migration of Ag atoms, driving hillock formation as the stress relaxes. Metal hillocks can nucleate at triplet junctions of grain boundaries, indicating pronounced grain boundary diffusion. ${ }^{20}$ Hillocks form much more easily on Ag films than $\mathrm{Cu}$ films because the grain boundary self-diffusivity of $\mathrm{Ag}$ is ten times faster than that of $\mathrm{Cu}^{21}$ Increasing the bonding temperature decreased the number of hillocks, although the hillock size sometimes increased, as shown in Fig. 4 . At $400^{\circ} \mathrm{C}$, we observed little hillock growth in the Ag film, as shown in Fig. 4. Instead, the Ag grains grew and voids formed uniformly on the Ag film surface. This behavior occurred because increasing the temperature drove lattice diffusion of $\mathrm{Ag}$ atoms inside the grains, causing lateral grain growth to dominate over hillock formation. This activated lattice diffusion introduces significant instability in grain growth; larger grains grow, while smaller ones are dissolved. At higher bonding temperatures of $350^{\circ} \mathrm{C}$ and $400^{\circ} \mathrm{C}$, only large grains are thus observed in the Ag film, accompanied with massive void formation, as shown in Fig. 4.

We measured the number and size of the hillocks grown on the $\mathrm{Ag}$ films heat treated at various bonding temperatures for $1 \mathrm{~h}$; Fig. 5 shows these as functions of the bonding temperature. The average hillock diameter increased with bonding temperature, while the number decreased. The shear strength depended on the bonding temperature, with the highest bond
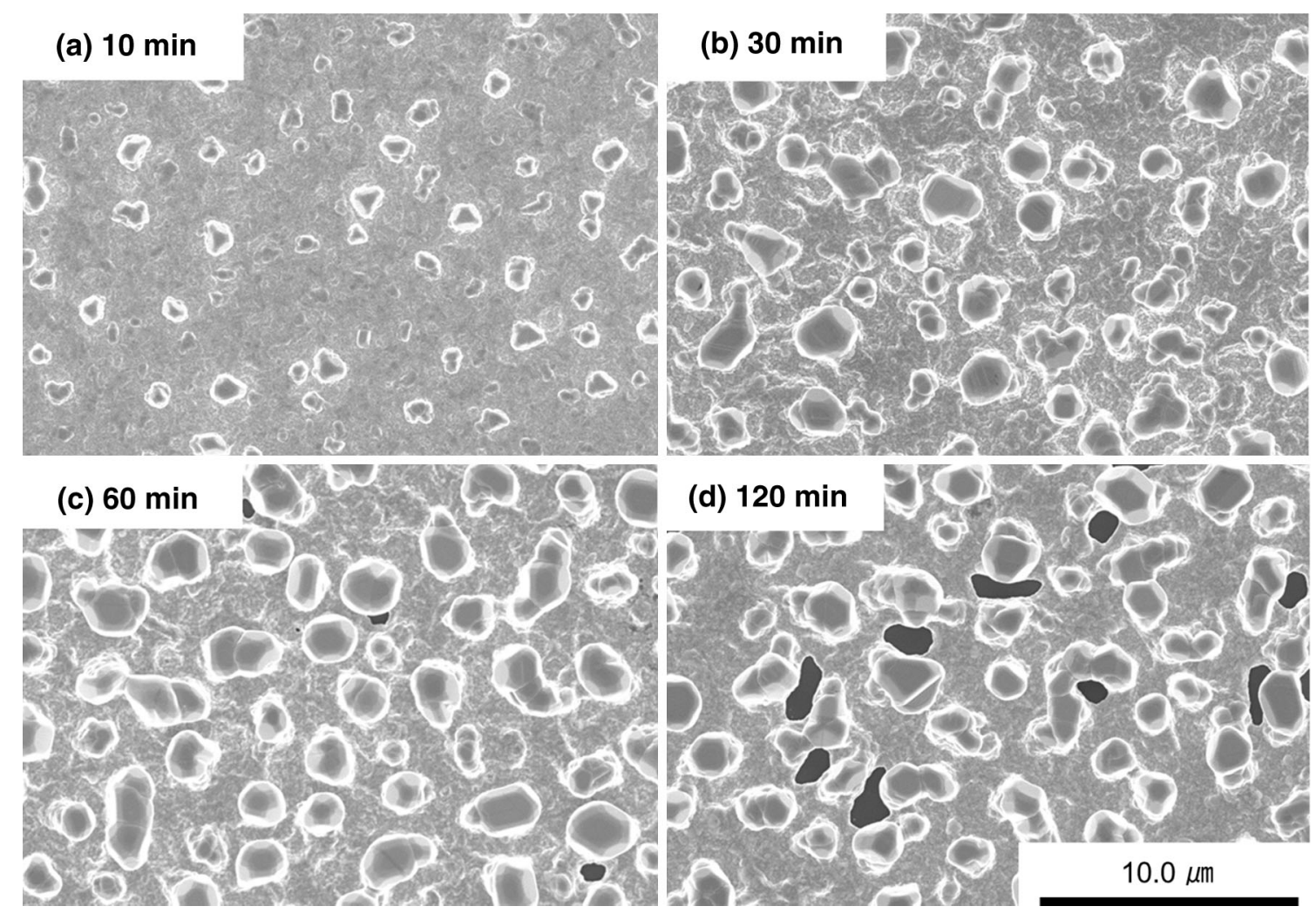

Fig. 6. SEM micrographs of microstructural evolution at various bonding times: (a) $10 \mathrm{~min}$, (b) $30 \mathrm{~min}$, (c) $60 \mathrm{~min}$, and (d) $120 \mathrm{~min}$. Ag hillock growth increased with bonding time and saturated after $60 \mathrm{~min}$. 
strength being achieved at $250^{\circ} \mathrm{C}$, the intersection of increasing hillock size and decreasing hillock number. The bonding process was successful at temperatures as low as $230^{\circ} \mathrm{C}$, which is very low for pressureless bonding. Moreover, the shear strength of $50 \mathrm{MPa}$ produced by our bonding method is much better than values produced by other bonding technologies. ${ }^{22}$ Note that the dependence of bond strength on the process temperature was closely related to the microstructure changes caused by the heat treatment, as shown in Fig. 4.

\section{Changes in Microstructural Evolution and Bonding Properties with Bonding Time}

Adopting an optimized process temperature of $250^{\circ} \mathrm{C}$, we investigated how varying the bonding

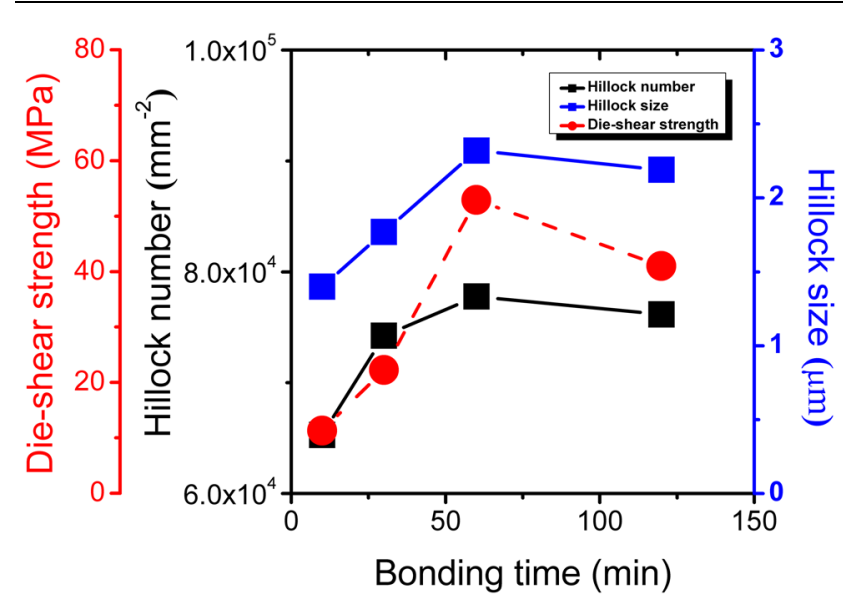

Fig. 7. Correlation among the size and number of hillocks and the die-shear strength of bonded samples at various bonding times. The bond strength is superimposed to show the relation between bond strength and hillock growth. The die-shear strength increased with bonding time up to $60 \mathrm{~min}$, then decreased slightly. time affected the microstructural evolution of $\mathrm{Ag}$ films, as shown in Fig. 6. The hillock number and size increased with bonding time. However, after 60 min, many more voids formed in the Ag film with little increase in hillock size. At times longer than $120 \mathrm{~min}$, the hillock size remained constant and the grains surrounding the hillocks grew slightly. Hillock growth appears to have saturated at bonding times exceeding 60 min.

Figure 7 shows the hillock number and size on the $\mathrm{Ag}$ films at $250^{\circ} \mathrm{C}$ as a function of the process time, with the bond strength superimposed. The bond strength increased greatly with process time up to $60 \mathrm{~min}$, then decreased slightly. This behavior agrees well with the hillock size and number on the film surface. The large areas of voids appearing after 60 min may have affected the bond strength, because a less dense structure formed, lacking obvious abnormal grain growth at the bonding interface. To ensure sound bonding, it is essential to optimize the heat treatment time to maximize hillock growth (i.e., abnormal grain growth) while also suppressing the formation of large voids at the bonding interface.

\section{Changes in Residual Stress with Bonding Conditions}

After the bonding heat treatment, the original compressive stress turned into tensile stress, as shown in Fig. 8. Stress relaxation in thin metal films during such heat treatment is usually caused by microstructural changes-in our case, hillock generation and grain growth-induced by thermal diffusion and accelerated by compressive stress. ${ }^{23}$ The stress in the Ag films changed considerably after heat treatment (Fig. 8), and the stress after heat treatment was about constant over all bonding conditions in this study, except at the shortest
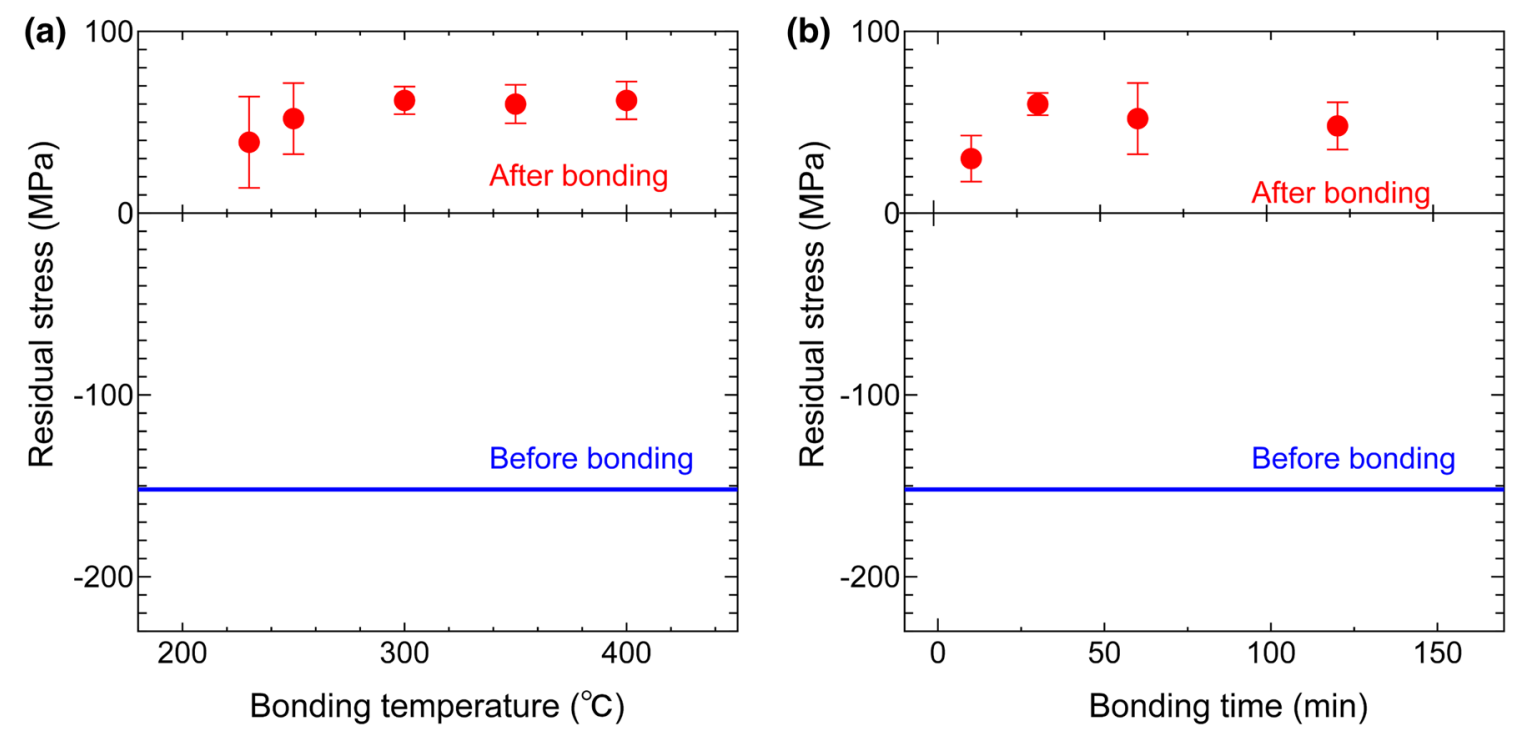

Fig. 8. Residual stress in Ag films before and after heat treatment at various (a) bonding temperatures and (b) bonding times. The stress changes remain about the same regardless of the bonding conditions. 
bonding time of $10 \mathrm{~min}$. This indicates that the driving force for compressive stress relaxation was almost independent of the range of processing conditions tested because of the inherent properties of the Ag films deposited under the same conditions. Thus, the microstructural changes in the Ag films during heat treatment depended on the temperature and process time, as shown in Figs. 4 and 6 . The microstructural changes essential for bonding were mainly caused by thermally activated atomic diffusion, which was strongly driven by the compressive stress accumulated during both film deposition and heating.

\section{CONCLUSIONS}

We studied pressureless Si wafer bonding, realized by abnormal grain growth on the surfaces of deposited Ag films. Fine columnar grains with (111) preferential crystalline orientation developed on the $\mathrm{Si}$ wafer. After heat treatment, we observed how the Ag film microstructure evolved (including hillock growth), how it varied over various bonding conditions, and how it related to the bond strength. The changes in the $\mathrm{Ag}$ film microstructure were driven by significant stress relaxation from compressive to tensile at the elevated temperatures. The highest bond strength was achieved when many large hillocks grew while maintaining the columnar structure inside the remaining film. These hillocks transformed into abnormally grown, large Ag grains, forming a sound bonding interface with extremely high shear strength. This bonding process was achieved at a relatively low temperature of $250^{\circ} \mathrm{C}$ without applying any load. We believe that our bonding method will cause little damage to semiconductor chips when used for die bonding in electronics packaging. Our pressureless bonding technology used with Ag thin films promises high reliability because of its low process temperature. It is a promising alternative to existing interconnection technologies, and it is suitable for a wide range of reliable power devices using next-generation semiconductors.

\section{ACKNOWLEDGEMENTS}

The authors are grateful for the support of the Japan Society for the Promotion of Science (Grantin-Aid for Scientific Research, Grant No. 24226017).

\section{REFERENCES}

1. Directive 2011/65/EU, http://ec.europa.eu/environment/waste/ rohs_eee/. Accessed 30 April 2014.

2. K. Suganuma, Curr. Opin. Solid State Mater. Sci. 5, 55 (2001).

3. K.W. Moon, W.J. Boettinger, U.R. Kattner, F.S. Biancaniello, and C.A. Handwerker, J. Electron. Mater. 29, 1122 (2000).

4. K. Suganuma, MRS Bull. 26, 880 (2001).

5. K. Suganuma, S.J. Kim, and K.S. Kim, JOM 61, 64 (2009).

6. S. Kim, K.S. Kim, K. Suganuma, and G. Izuta, J. Electron. Mater. 38, 873 (2009).

7. V. Chidambaram, J. Hattel, and J. Hald, Microelectron. Eng. 88, 981 (2011).

8. H.A. Mustain, W.D. Brown, and S.S. Ang, IEEE Trans. Compon. Packag. Manuf. Technol. 33, 563 (2010).

9. N.S. Bosco and F.W. Zok, Acta Mater. 53, 2019 (2005).

10. K. Suganuma, S. Sakamoto, N. Kagami, D. Wakuda, K.-S. Kim, and M. Nogi, Microelectron. Reliab. 52, 375 (2012).

11. D. Wakuda, K.S. Kim, and K. Suganuma, IEEE Trans. Compon. Packag. Manuf. Technol. 32, 627 (2009).

12. Y.S. Tang, Y.J. Chang, and K.N. Chen, Microelectron. Reliab. 52, 321 (2012).

13. T.H. Kim, M.M.R. Howlader, T. Itoh, and T. Suga, J. Vac. Sci. Technol. A 21, 449 (2003).

14. M. Kuramoto, T. Kunimune, S. Ogawa, M. Niwa, K.S. Kim, and K. Suganuma, IEEE Trans. Compon. Packag. Manuf. Technol. 2, 548 (2012).

15. T. Kunimune, M. Kuramoto, S. Ogawa, M. Nogi, and K. Suganuma, IEEE Trans. Compon. Packag. Manuf. Technol. 3, 363 (2013).

16. C. Oh, S. Nagao, T. Kunimune, and K. Suganuma, Appl. Phys. Lett. 104, 161603 (2014).

17. R. Daniel, D. Holec, M. Bartosik, J. Keckes, and C. Mitterer, Acta Mater. 59, 6631 (2011).

18. Y.A. Chang and L. Himmel, J. Appl. Phys. 37, 3567 (1966)

19. J. Greiser, P. Müllner, and E. arzt, Acta Mater. 49, 1041 (2001).

20. D.K. Kim, W.D. Nix, R.P. Vinci, M.D. Deal, and J.D. Plumer, J. Appl. Phys. 90, 781 (2001).

21. Chr. Herzig and S.V. Divinski, Mater. Trans. 44, 14 (2003)

22. J. Yan, G. Zou, A.-P. Wu, J. Ren, J. Yan, A. Huc, and Y. Zhou, Scripta Mater. 66, 582 (2012).

23. W.D. Nix, Metall. Trans. A 20A, 2217 (1989). 